\title{
The Hidden Curriculum of Teacher Training
}

Yochanan Eshel, Dept. of Psychology

Haifa University

\begin{abstract}
This opinion paper relies on classic and current literature as well as the author's own expertise and perspective to propose a few core agenda points for teacher education and training in current contexts. It is suggested that although the Israeli (as well as other) education systems has systematically refrained from phrasing and implementing a comprehensive, strategic view of what education should be all about the emerging themes may serve as underlying guidelines for current and future teacher education program.
\end{abstract}

\section{Keywords}

teaching, teachers, curriculum,

opinion letter 
In Meno, one of Plato's Socratic dialogues, the author presents the question of whether virtue can be taught or is inherent?

Teacher training programs are based on the assumption that students can be trained to be teachers, but it is not clear whether these programs all agree about the definition of a teacher's characteristics (or virtues, if one prefers and Platonic approach), the main goals of teachers' training, and the way by which these goals should be implemented by future teachers. Every teacher training college's curriculum emphasizes the disciplinary field of knowledge which the students need to acquire within their chosen program, as well as the classes and practical work they are required to take part of in order to complete their pedagogical training. However such programs are often very technical in nature, dividing the student's training time into content matter, pedagogical and experiential-internship style hours, lacking what could be described as a holistic view of who their graduates should become upon completing the program. That is what I call "the hidden curriculum".

A further examination would reveal that the criteria briefly mentioned above, are prioritized differently in every teaching college, and each college underlines a different educational goal which is meant to portray its unique teacher training method. Thus for example, one teaching college highlights the value of the teacher's social involvement; another advocates training the teacher as a leader, a third college sees the training essence in passing knowledge and values to future generations; a fourth college believes in advancing the teacher's qualities as a sensitive, contemplative, investigative, creative and initiative education professional, and an additional college stresses the importance of training the teacher to serve as a motivator to self-fulfillment for their students. These educational goals constitute the hidden curriculum of every college. Although these goal are not specified explicitly in official college's curricula, they function as major goals, guiding faculty and students alike, as well as define the teacher's perceived persona, which the college aspires to pass on to its students.

The educational literature has made a significant effort to address the issue of what are the aims and goals of teacher preparation, which would turn a teaching trainee to a mentor for generations of pupils. This literature as well as its implementation in different colleges' programs reflects a set of goals that seem to constitute corecriteria for the preparation of future teachers. I will now review these goals briefly.

One major goal is to train a teacher who succeeds in developing unmediated, sincere relationships with their students that are based in trust and mutual respect. Such a teacher makes sure that the environment in their class is warm, inviting and safe for learning. A teacher, who sets an example for all of their students, is characterized by genuine care for the other, warmth, openness and a willingness to listen and help. They sustain an on-going dialog with the student, which increases their motivation and involvement in the learning process, and their motivation and commitment to study and learn, beyond the formal requirements.

A second goal is educating for values. This goal emphasizes the teacher's main role as an agent of sociocultural change. As such their goal is to encourage learners to examine social norms and values with a critical eye, weigh the pros and cons of ethical decisions and develop and personal, individual point of view based on values to create socially involved students, and to instill the acknowledgement in the idea that in order to live a meaningful life, they must live their lives following the values they believe in. The problematic nature of this goal results from the question of the definition of appropriate values. One approach suggests that a good teacher must educate for values which are culturally stable, and their endurance through generations validates their necessity and importance to the individual and their society. Another approach, however, would aspire to encourage a 
critical attitude towards the values and behavior codes that are accepted in society, and to encourage learners to believe that their role is to improve their society, and nurture their intellectual integrity, by which they would be able to reveal flaws within the current value system, as they work to improve it through individual and social change.

A third educational goal relates to the teacher's role in the development of the student's personality, skills and so-called 'ego functions'. Students attend school through the most important years of their individual formation and transitions from childhood to early adulthood. Such transition involves dramatic changes in the physiological, cognitive, behavioral and interpersonal arenas. Teachers can be expected to facilitate and support these processes helping students successfully cope and adapt to the changes and challenges of development and make the most of them. Such guidance may help learners achieve self-fulfillment; actuate their full potential, define their self- identity, crystalize their fundamental attitude towards themselves and their own destiny. This kind of teacher would encourage their students to assume responsibility for their lives and their future choices, to confront their mistakes and failures in a manner that will allow growth and development. In order to achieve all of the above, the teacher will nurture students' critical and divergent thinking ability, as well as the motivation to ask questions and understand ideas and concepts in-depth. A teacher who practices this approach must accept the possibility that they would be compelled to advance the self-fulfillment of students whom they may not approve of, or help young individuals pursue lines of thought and action that they, personally, may see as misguided. Suspending judgement within the boundaries set by ethics and law is challenging not only for the students, but mainly for the teachers who find themselves in a very sensitive and important crossroads.

A fourth goal which may be a key factor in teacher training is developing class-management skills. In most cultures and especially in the Israeli settings, discipline, and keeping a climate of learning can at times be a major challenge. To reach organizational goals set by policy and curricula, teachers have to show effective classmanagement skills, and to effectively cope with disruptive behavior. According to this approach, the teacher understands that above all, they are in charge of advancing their students' development and achievements, and knows that it is impossible to reach this goal if they lack the skills to organize and manage the learning environment within a set of rules and boundaries. Such teacher properly uses the time dedicated for teaching, constantly supervises their students' learning process, is able to instill discipline in the classroom and is proficient in methods and techniques of maintaining order while containing disruptive behavior to minimize damage and even provide opportunities for learning and development from such instances and events.

There are two main obstacles undermining the realization of the above goals, among others: The first obstacle results from the fact that teaching students are already adults when they enter their training: Already quite set in their ways, their attitudes and world-views. Thus, it is doubtful whether there is an applicable way to provide them with a specific educational point of view and to realize it during their college training program. Furthermore, such endeavor would require dedicated measures (some already in existence but many will have to be developed and validated within various settings, such as personal values, ego maturity etc.) to be implemented as part of the selection process for teaching candidates as well as a part of the training and assessment program.

The second obstacle stems from the inherent gaps between the goals that may emerge as core expectations typical of most teacher colleges' programs and curricula and the goals of individual faculty at a given college. The academic culture fostering academic freedom means that faculty members are not expected to fully commit to the values and norms promoted by the institutions for which they work. While this value is important in 
maintaining freedom of thought and academic progress, it may undermine the very practical goals described above, since they do not necessarily identify and endorse them. Every faculty member in a teaching college has probably formed a personal educational perspective over the years, which reflects their own set of values and educational goals that they wish to pass on to their students. These goals do not necessarily match the major goals chosen and promoted (formally or informally) by the college. It also stands to reason that each faculty member would have a slightly different educational perspective, and that each would aspire to establish and promote these values and goals among their students.

It is therefore almost a given that within a democratic society that believes that each member of the faculty has the right to hold their own educational perspective, promotes diversity and does not aspire to enforce a unified educational set of goals on their members, teaching students would be exposed to varying methods and goals and would be required to understand, judge and choose their own approach and way, as a means to start establishing their own educational perspective, with accordance to their own individual qualities, skills, and value system. As they make their way through the curriculum, developing as individuals and future professionals they form ideas as to the kind of teacher they would want to become. This situation, which probably characterizes most colleges, might create a gap between the declared or formal major goals of teaching colleges, and the teaching and learning processes that actually take place in them.

An intellectual community of college faculty should not perceive the current situation as a violation or disturbance in the way "things should be", but rather as an opportunity for starting a debate regarding educational questions, such as: Who are our graduates? What are they equipped with in terms of knowledge, skills and proficiencies as well as belief systems and values? do we know what are the educational messages that we deliver to our students? To what extent are faculty in charge of shaping young people's values and world-views? and to what extent should we minimize our role when it comes to suggesting a philosophy of education and ways of thinking, and let them chose their own future educational perspective and methodology on their own? Would it be right to focus on one major goal and put a great deal of effort into it, or promote numerous goals by 'planting seeds' that may or may not yield fruit in the future? And finally, how much diversity can the curriculum contain? do we, as education professionals, have binding boundaries, which we must never breach? Furthermore, the question remains whether college lecturers should deal with these questions, or that every lecturer is committed to an optimal level of teaching within their field of expertise, and should not be dealing with the philosophical question of defining criteria for good teachers.

The purpose of such debate is not reaching an agreement, but to expose self and colleagues' points of view and to have a better understanding of the educational reality which we create and live in. If we wish to nourish a broad, critical and an independent way of thinking among our students, then it is highly important to apply a similar process among the faculty regarding the professional and ethical boundaries of teaching college faculty, and the relevance of the primary goals to teachers' work. In a complex and often contradictory reality that allows merely a partial control over process as well as outcomes in education in general and teacher preparation in particular, occasionally there is a higher significance to asking the questions and understanding the main educational dilemmas rather than reaching solutions accepted by all. 